\title{
Online remote-controlled and cost-effective fouling and clogging surveillance of a groundwater heat pump system
}

\author{
A case study from Lena Terrace in Melhus, Norway.
}

\author{
Sondre Gjengedal ${ }^{1}$ (D) $\cdot$ Lars A. Stenvik $^{1} \cdot$ Randi K. Ramstad $^{1} \cdot$ Jan I. Ulfsnes $^{2} \cdot$ Bernt O. Hilmo $^{3} \cdot$ Bjørn S. Frengstad $^{1}$
}

Received: 4 December 2019 / Accepted: 25 August 2020 / Published online: 10 September 2020

(C) The Author(s) 2020

\begin{abstract}
Fouling and clogging of groundwater wells and heat exchangers are among the major operational challenges for groundwater heat pump (GWHP) and aquifer thermal energy storage (ATES) systems. This article presents the application of a step-test surveillance procedure developed for early detection of clogging in distinct parts of the GWHP system, tested at Lena Terrace in Melhus Norway. Three versions of the test procedure are presented and demonstrate that the test can be performed with a minimum of four steps, each of 15-min duration, while the GWHP system is actively producing heat. The results prove that the surveillance test can detect changes in the hydraulic resistance of the groundwater circuit and locate clogging problems within all of the relevant system components in the groundwater circuit simultaneously. At the Lena Terrace GWHP system, these tests indicate a gradual increase of hydraulic resistance with time, which verify that clogging issues are continuously developing in the injection well, in the production well, and in the groundwater heat exchanger. Cleaning of the heat exchanger was then performed. This increased the pumping capacity by $8.3 \%$ points, but continuous clogging of the injection well and the production well necessitates further maintenance to ensure a reliable operation. It is demonstrated that multidisciplinary competence and experience with GWHP-systems, aquifers, and groundwater wells are needed for the evaluation of the results. These results can therefore serve as a reference for other GWHP systems with similar design configurations.
\end{abstract}

Keywords Groundwater $\cdot$ Step-test $\cdot$ Clogging $\cdot$ Surveillance $\cdot$ Hydrogeology $\cdot$ Heat pumps

\section{Introduction}

Ground water heat pump (GWHP) systems have become increasingly popular in Norway during the latest decades. Recent studies indicate a large potential for this technology, and similar trends are also seen worldwide (Bloemendal et al. 2015). One of the largest consumers of GWHP heating and cooling in Norway is the municipality of Melhus. An aquifer beneath the town center of Melhus is currently utilized as a heat source by ten individual GWHP systems. The first installation started

Sondre Gjengedal

sondre.gjengedal@ntnu.no

1 Norwegian University of Science and Technology, Trondheim, Norway

2 Optiview AS, Vihals, Norway

3 Asplan Viak AS, Trondheim, Norway production already in 1999 and is still in operation today. All of these GWHP systems use a Quaternary deposit of saturated sand and gravel material as their heat source.

Many aspects of the system performance are governed by the local and the overall hydrogeological conditions within this deposit. The groundwater quality is an important factor in all types of GWHP installations (Bakema 2001; Banks 2012; Snijders and Drijver 2016). Problems caused by chemical reactions, suspended soil particles, or microbial growth in the water are a well-known and widespread issues for these systems, and clogging and fouling of system components is a common problem in Melhus (Riise 2015; Brøste 2017; Gjengedal et al. 2018; Gjengedal et al. 2019a; Gjengedal et al. 2019b). These problems typically involve clogging of the groundwater heat exchanger, the well screens, the pipeline, and the aquifer formation, also causing increased fatigue and erosion of the submersible pump. Usually, the heat pump performance and overall cost of the operation are affected by reduced heat production capacities and efficiencies. In severe 
cases, the complications can lead to complete system failure. Fouling and clogging of groundwater wells and heat exchangers therefor put the long-term reliability and sustainability of GWHP and, similarly, aquifer thermal energy storage (ATES) systems at risk. Consequently, groundwater source systems require a higher level of surveillance and maintenance than other ground source heat pump systems (Banks 2012; Snijders and Drijver 2016; Gehlin and Andersson 2019).

Monitoring and surveillance of GWHP systems is typically carried out by recording and analyzing pressure, temperature, and volume flow rate data (Gjengedal et al. 2019a). This type of monitoring is common in many heat pump applications (Stene 2001; Rees 2016) and is also standard for many industrial heating and cooling applications. District heating applications and the oil \& gas industries are some examples (Müller-Steinhagen 2000; Melo et al. 1988). However, a variety of clogging and fouling issues in GWHP systems can cause similar symptoms and data responses, hence making it challenging to evaluate the data correctly.

A surveillance procedure for early detection of clogging and fouling in GWHP systems has previously been developed for GWHP systems in particular (Gjengedal et al. 2019a). Gjengedal et al. (2019a) demonstrate that the dynamic behavior of GWHP systems requires the pressure, temperature, and volume flow rate data to be evaluated with a specific procedure to enable proper interpretation of the data. The suggested procedure allows for testing and evaluation of all of the individual system components in the GWHP system simultaneously. The procedure has now been applied regularly in one of the installations in Melhus during routine maintenance of the system. This paper presents the experiences with the surveillance method and demonstrates the usefulness of the method for performance monitoring.

\section{Site description and system specification}

The town of Melhus is located in the Gauldal valley in MidNorway, approximately $20 \mathrm{~km}$ south of the city of Trondheim (Fig. 1). The town is located on a floodplain next to the river Gaula. Immediately to the north of the populated area, the landscape is dominated by Melhusryggen, a forested terminal moraine that stretches halfway across the valley, from the mountain of Vassfjellet in the east to the eastern embankment of the river Gaula. This glaciofluvial ridge marks the upper part of the Quaternary sand and gravel deposit known as the Melhus aquifer, an aquifer that in part extends beneath the town center south of the ridge. The river Gaula intersects the town center and separates both the town center and the aquifer into a western and eastern part.

Today, this aquifer supplies ten individual building complexes with heat and three building complexes with both heating and cooling. The Lena Terrace apartment complex was built in 2003. It is located at the foot of the Melhusryggen ridge and is highlighted as the case study site in Fig. 1. The apartment complex' GWHP system is designed as a reinjection type system (Fig. 2). The local sediments are dominated by unconsolidated sand and gravel of glaciofluvial origin, and the groundwater water table is located approximately $20-21 \mathrm{~m}$ below the terrain level. At this depth and location within the aquifer, the groundwater temperature is found to be stable all year round at $\sim 7{ }^{\circ} \mathrm{C}$. The "natural" groundwater level, which imply the water level unaffected by the local GWHP activity, fluctuates approximately \pm $1.0 \mathrm{~m}$ throughout the year (Hellestveit 2018). The aquifer is accessed by the GWHP system through two groundwater wells, one production well, and the other an injection well. The permeability of the aquifer formation is high, and this is reflected in the design of the wells.

The production well design is customized to the local soil conditions. The original design was a larger $219 \mathrm{~mm}$ OD well size, but due to drilling problems, the well size was reduced during construction. The finalized well design is 36.4-m deep and has a steel casing width of $168-158 \mathrm{~mm}$ (ODxID). The water is extracted from the well by a $10.8 \mathrm{~kW}$ Grundfos SP 60-5-MS6000 $(50 \mathrm{~Hz})$ submersible pump, which is installed at $28 \mathrm{~m}$ depth, immediately above the well screen. The well screen is the perforated section of the well and is installed from 29.4 to $35.4 \mathrm{~m}$ depth, providing $6 \mathrm{~m}$ of screened well length. The screen is a $161-150 \mathrm{~mm}$ ODxID con-slot screen, with $1.0 \mathrm{~mm}$ slot openings and a $31.3 \%$ perforation ratio. This screen design was selected based on grain size analysis of the soil, which are dominated by medium to coarse sand and gravel particles.

This production well design was originally selected to ensure proper operating conditions for the submersible pump. The Grundfos SP $60-5$ pump generally requires $4-5 \mathrm{~m}$ of net pressure suction head (NPSH) during production (NPSH required depends on the motor speed). When the pump is inactive, the water table in the well is typically $6.0-7.0 \mathrm{~m}$ above the submersible pump. The available drawdown is thus limited to 2 $3 \mathrm{~m}$, leaving limited margin for potential clogging issues. There is however a $0.5-\mathrm{m}$ sump pipe installed beneath the screen to accommodate potential sediment suffusion during operation.

The injection well is 36.5-m deep and has an identical design, but the screened segment of the well is installed from 23.5 to $33.5 \mathrm{~m}$ depth, which provide $10 \mathrm{~m}$ of screened well length. The return pipe is installed at $27.5 \mathrm{~m}$ depth, in the middle of the screened section of the well. There is a $3-\mathrm{m}-$ long sump pipe beneath the screen to accommodate potential sediment suffusion during operation. The natural water table is typically $18.0-19.0 \mathrm{~m}$ below the well top during the heating season. This large elevation drop towards the well water level generates a suction in the groundwater piping system during production, causing vacuum pressures to develop in the pipe and in parts of the surface installation. 


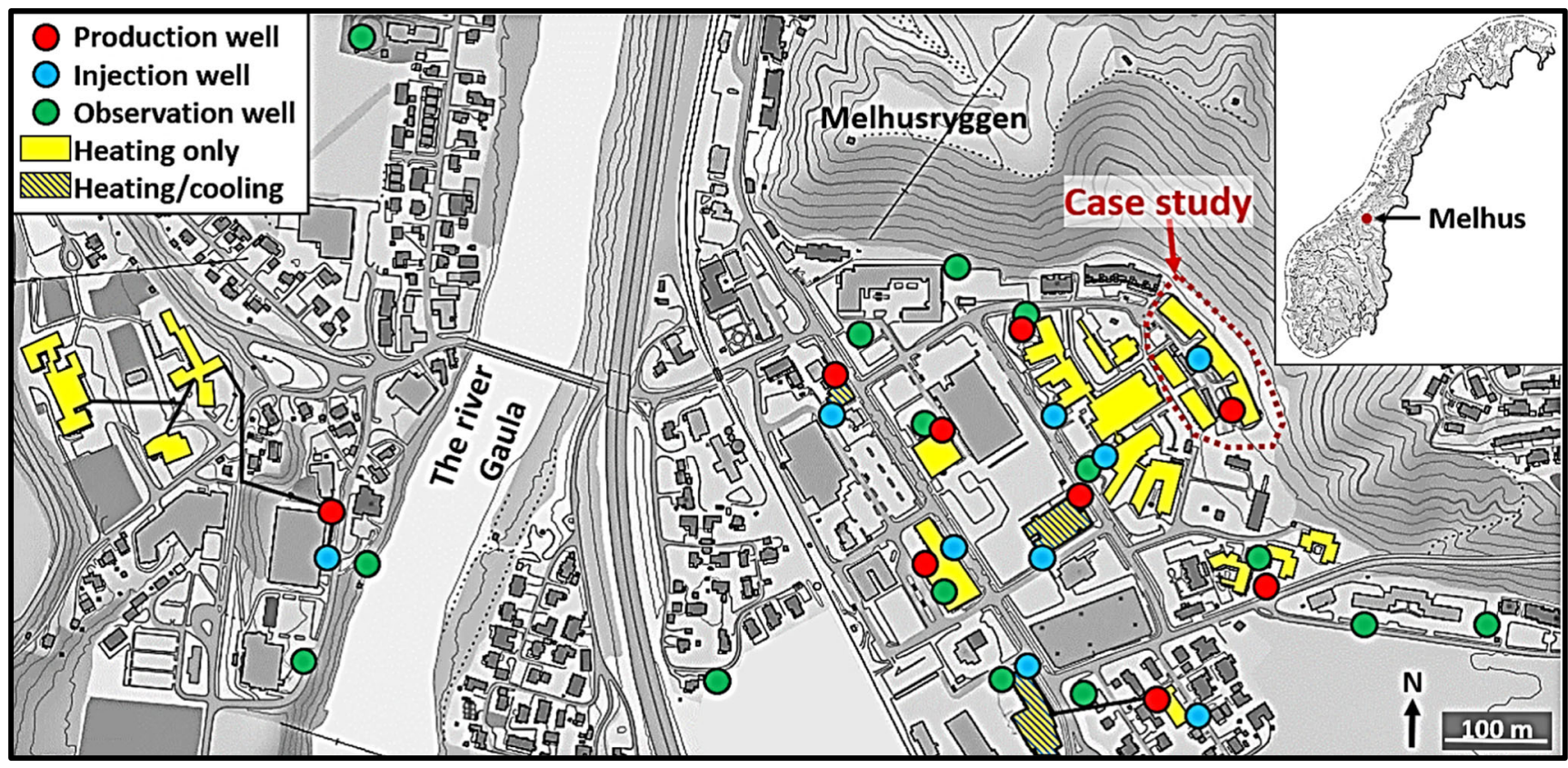

Fig. 1 Overview of the town center of Melhus with the ten GWHP installations (yellow buildings) and the corresponding groundwater wells indicated. There are 34 groundwater wells in the area, of which

The groundwater circuit part of the surface installation is visualized in Fig. 3. The system consists of approximately $100 \mathrm{~m}$ of $160 \mathrm{~mm}$ ID HDPE pipes that connect the two wells to the groundwater heat exchanger situated in the basement of the building. The groundwater heat exchanger is a $260-\mathrm{kW}$ gasket plate heat exchanger with a total of $72 \mathrm{~m}^{2}$ plate surface
18 are used for heating and cooling purposes. The location of the Lena Terrace building complex is highlighted as the case study site. Details of the Lena Terrace GWHP system are provided in Fig. 2 and Fig. 3

area (1.3 fouling factor). The total peak heating demand of $350 \mathrm{~kW}$ is provided by two custom Chiller Oy heat pump units (R134a). The heat pumps are coupled in parallel to a secondary loop circuit with $20 \%$ ethylene glycol antifreeze fluid. The secondary loop is connected to a plate heat exchanger for heat transfer with the groundwater loop.

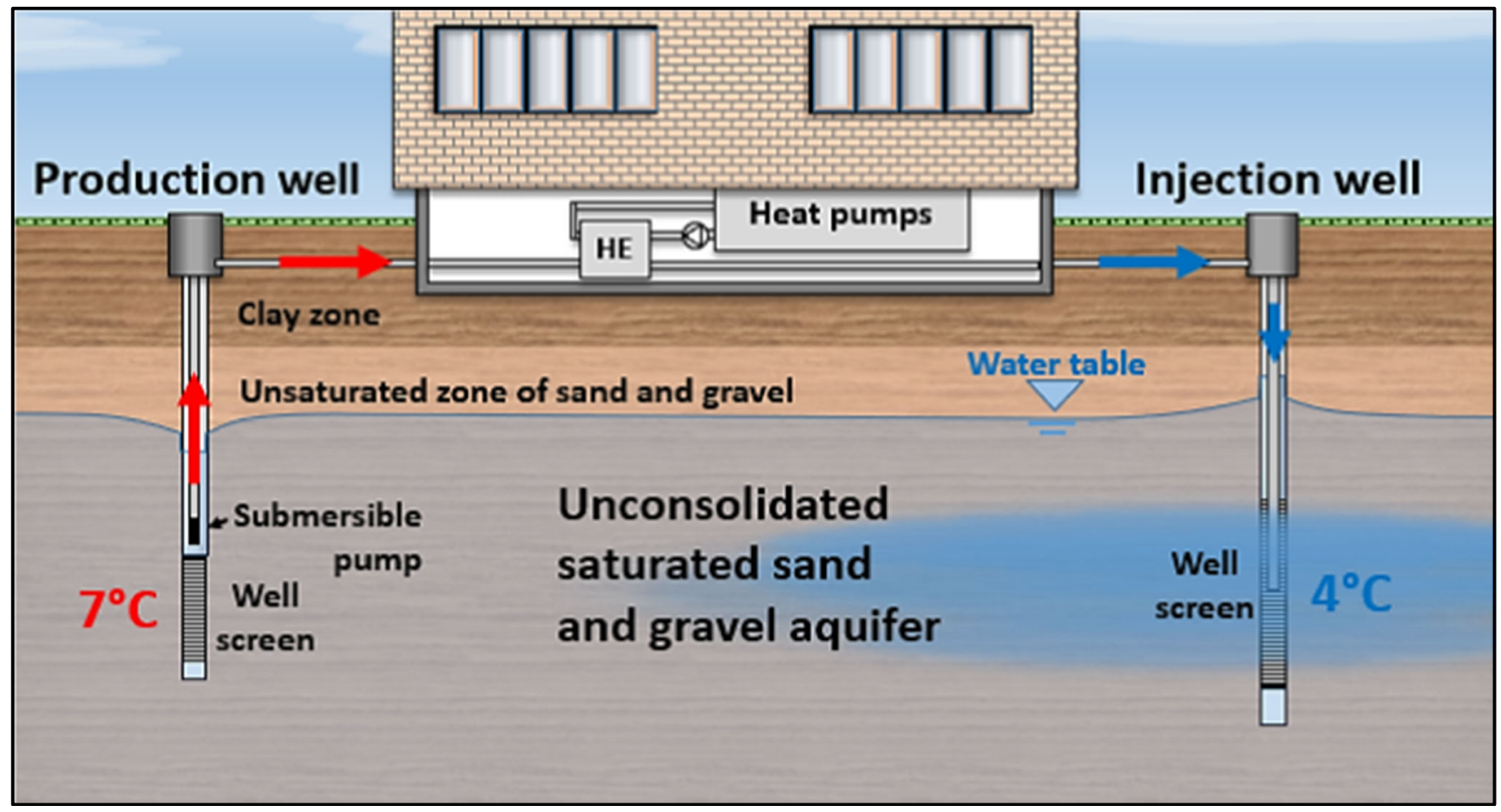

Fig. 2 Schematic sketch of the soil conditions and the reinjection type GWHP system employed at Lena Terrace in Melhus, Norway (the sketch is not to scale) 


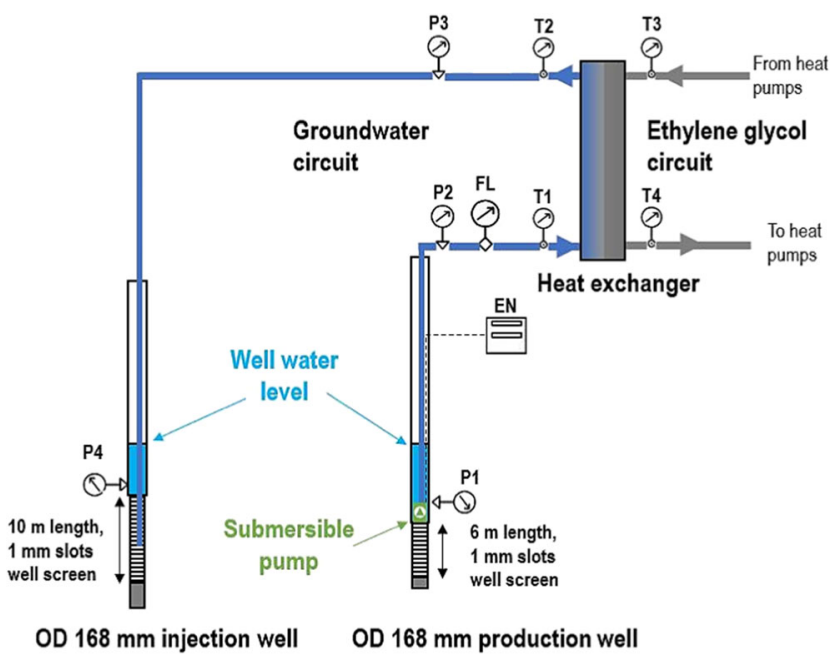

Fig. 3 Schematic sketch of the GWHP system at Lena Terrace, including real time monitoring of operational parameters. The groundwater pipe segment is approximately $100 \mathrm{~m}$ long. The relative location of the pressure transducer $(\mathrm{P} 1-4)$, the flow meter $(\mathrm{FL})$, the energy meter (and frequency converter) of the submersible pump (EN), and the temperature sensors (T1-4) are shown. The sketch is based on the online OPTIVIEW® interface

The designed efficiency point for the whole system is a coefficient of performance of 3 at maximum heating capacity $(\mathrm{COP}=3)$. The groundwater system is designed to supply approximately $18 \mathrm{l} / \mathrm{s}$ of groundwater to accommodate the thermal demand during peak load conditions in the winter months. It assumed a groundwater temperature reduction from $7{ }^{\circ} \mathrm{C}$ to $4{ }^{\circ} \mathrm{C}(\Delta \mathrm{T}=3 \mathrm{~K})$ at these conditions. During part load conditions, in the autumn and spring, the amount of groundwater circulation is reduced. This is controlled by adjusting the operating point of the submersible pump, between 60 and 100\% of the maximum pump motor frequency $(30-50 \mathrm{~Hz})$.

Since its construction in 2003 the Lena Terrace GWHP plant has been affected by a variety of clogging and fouling issues. These are recurring problems, where fouling of iron precipitates affects the heat exchanger, while soil particles clog the injection well. The heat exchanger was most recently replaced in 2018 because of insufficient heat transfer capacity. The injection well is cleaned annually, most recently in 2018 and 2019, in an effort to maintain the reinjection capacity. Following the latest rehabilitation measures in 2018, the installation was re-equipped with new sensory equipment to improve the monitoring. These sensors are visualized in Fig. 3. The implementation of an automated control system now allows for remote control of the installation through an online TOSIBOX® system.

It is planned to clean the heat exchanger annually with an organic acid treatment before each heating season to mediate the iron precipitation fouling problem. The step-test method data presented here was applied in a period before and after the cleaning treatment on the 8th-9th of October 2019, to evaluate the need and the effect of the acid treatment. Three of these step-tests are presented in this paper. The two first tests were conducted before the fouling treatment of the heat exchanger, while the third test was performed after the treatment.

\section{Methodology}

The surveillance procedure employed in this study involves conducting a series of incremental adjustments to the motor speed of the submersible pump, a so-called step-test. This is done by remote control through the online TOSIBOX® system, where the motor speed is controlled between 60 and $100 \%$ of its pumping capacity. The hydraulic and thermal performance of the system is then simultaneously measured at each speed, and the data is evaluated with least square regression analysis. The data response is evaluated with regard to potential clogging and fouling issues that affect the performance of the system in distinct ways, depending on their location within the system, as described in Gjengedal et al. (2019a).

The control system's integrated monitoring and control instrumentation are used for the data acquisition. The instrumentation and their relative location in the relevant part of the system control interface are shown in Fig. 3. The sensors used in the instrumentation are further described in Table 1. The temperature (T1-T4), pressure (P1-4), flow rate (FL), and the pumping power $(\mathrm{EN})$ at the various speeds were recorded at each step of the test. All sensory data was automatically recorded by the monitoring system each minute and stored. The input data for the least square regression analysis and calculations are average values of the last eight measurements of each step of the tests, where steady-state conditions were assured.

The step-test procedure follows the methodology described in detail in Gjengedal et al. (2019a). Three variants of the procedure were tested to evaluate the applicability of the method (Table 2). The first test was performed with the minimum three steps required for the method, each of the steps having a duration of $1 \mathrm{~h}$. Traditionally, each step of the tests is recommended to be between 0.5 and $2 \mathrm{~h}$ (Kruseman and de Ridder 1994), but the time can be reduced if the pressure response reaches steady state earlier. The purpose of test 1 was to evaluate the timeframe needed to achieve steady-state flow and pressure responses in the wells and the piping system. The pressures response stabilized within the first 1-3 min for each step, indicating a highly permeable aquifer formation. The duration of each step could therefore be reduced to $15 \mathrm{~min}$ for the two consecutive tests to investigate the possibility of reducing the timeframe of future tests.

The second test was performed with 19 individual steps to see if more steps would provide higher accuracy and possibly improve the usefulness of the surveillance data. The third test was an intermediate version with six steps. For tests 1 and 2, 
Table 1 Instrumentation relevant for the step-test surveillance procedure

\begin{tabular}{lll}
\hline Location in Fig. 3 & Instrument type & Accuracy \\
\hline P1 & Pressure transducer, Siemens SITRANS LH100 & \pm 0.0015 bar \\
P2, P3 & Pressure transducer, Danfoss MBS 4010 0-6 BAR ABS & \pm 0.03 bar \\
P4 & Pressure transducer, Kacise GXPS430 & \pm 0.015 bar \\
FL & Flow meter, Badger ModMAG M1000 & $\pm 0.041 / \mathrm{s}$ \\
EN & Energy meter, Grundfos CUE 3X380-500 V IP55 15KW 32A/2 & - \\
T1-T4 & Temperature probes, PT1000 & $\pm 0.3{ }^{\circ} \mathrm{C}$ \\
\hline
\end{tabular}

See Fig. 3 for the relative location of the instruments in the GWHP system the system was shut off before the tests to measure the unaffected pressure responses. Test 3 was performed without a shutoff period before the test, due to the continuous heat demand in the building. The unaffected groundwater level was then estimated via inverse calculation, using tests 1 and 2 as a reference for the expected water level draw-down at $60 \%$ pump capacity.

The procedure for test 2 is demonstrated in Fig. 4 and visualizes the progression of the test procedure. The test is performed with a pyramid-shaped speed increment adjustment. The first and the last step have the same speed (60\%), while incremental adjustments were distributed evenly and mirrored around the $100 \%$ speed, producing the pyramidshaped power curve. This mirroring of the test provided a mean of control during the test and confirmed that the behavior of the system is unchanged throughout the test procedure. Similar performance "pyramids" were observed in the data response in the control instrumentation.

\section{Results}

The four temperature sensors (T1-T4 in Fig.3) are installed on the four heat exchanger pipe segments to measure the temperature development of both fluids through the heat exchanger. In ideal conditions, the temperature data should be included in the analysis, but these temperature sensors were found to be incorrectly calibrated and could not be used to determine the efficiency of the heat exchanger. Thus, primarily the hydraulic performance of the system, with the pressure, energy meter, and flow meter data, is used in the performance analysis.

The pyramid shape of the test 2 procedure (Fig. 4) is reflected in the pressure response that is presented in Fig. 5 for the heat exchanger. The differential pressure between the two sensors describes the hydraulic losses through the heat exchanger, which is used in the regression analysis. The data also demonstrate that the groundwater heat exchanger is subjected to vacuum pressures if the groundwater flow rate is reduced below a given threshold value (red shaded area in Fig. 5). This is observed in the P3 sensor when the groundwater flow rate is lower than $10.0 \mathrm{l} / \mathrm{s}$, which corresponds to the $80 \%$ step in Fig. 4. At the lowest step (the $60 \%$ step), a $-7 \mathrm{kPa}$ gauge pressure is observed in the $\mathrm{P} 3$ sensor. When the pump is turned off, the vacuum extends to the whole surface installation and stabilizes at approximately $-70 \mathrm{kPa}$ gauge pressure in both P2 and P3.

The results of the regression analyses of the three step-tests are presented in Table 3 and visualized in Fig. 6. The test results show that the electrical power consumption of the groundwater pump is equal for each corresponding step for each test, but the corresponding flow rates vary. A reduction in the pumping capacity signifies that the pump produces less water at a given motor speed. This can be observed by comparing the $100 \%$ speed flow rate of each test in Fig. $6 \mathrm{~d}$. In test 1 , the flow rate is $16.2 \mathrm{l} / \mathrm{s}$, which is $10 \%$ reduction from the initial $18.0 \mathrm{l} / \mathrm{s}$ capacity of the system. For test 2 , the maximum capacity has reduced to $15.7 \mathrm{l} / \mathrm{s}$, corresponding to a further $3.0 \%$ point reduction in pumping capacity over a 41-day

Table 2 The step-test specification for each of the three tests

\begin{tabular}{|c|c|c|c|c|c|c|c|}
\hline $\begin{array}{l}\text { Test } \\
\text { no. }\end{array}$ & Date & Test time $[\mathrm{h}]$ & No. steps & Time per step [min] & Start point $[\%$ of $50 \mathrm{~Hz}]$ & Increment [\% points] & Shutoff \\
\hline 1 & $\begin{array}{l}28.08 .2019 \\
\text { (Reference test) }\end{array}$ & 4 & 3 & 60 & $0 \%$ & 20 & Yes \\
\hline 2 & $\begin{array}{l}08.10 .2019 \\
\text { (41 days later) }\end{array}$ & 5.5 & 19 & 15 & $0 \%$ & $2-3$ & Yes \\
\hline 3 & $\begin{array}{l}16.10 .2019 \\
\text { (55 days later) }\end{array}$ & 1.5 & 6 & 15 & $60 \%$ & 10 & No \\
\hline
\end{tabular}

The various steps were distributed evenly through the $60-100 \%$ speed intervals, $60 \%(30 \mathrm{~Hz})$ is the minimum speed and $100 \%(50 \mathrm{~Hz})$ is the maximum speed of the pump. All measurements were automatically recorded each 1 min by the monitoring system 
Fig. 4 Step-test procedure of test 2 at Lena Terrace GWHP system. The test involves 19 steps of incremental pumping speed adjustments between 60 and $100 \%$ of the pump power capacity. The first and final step are at the $60 \%$ speed. Each step lasts for $15 \mathrm{~min}$. The test is completed with a shutoff sequence at the end

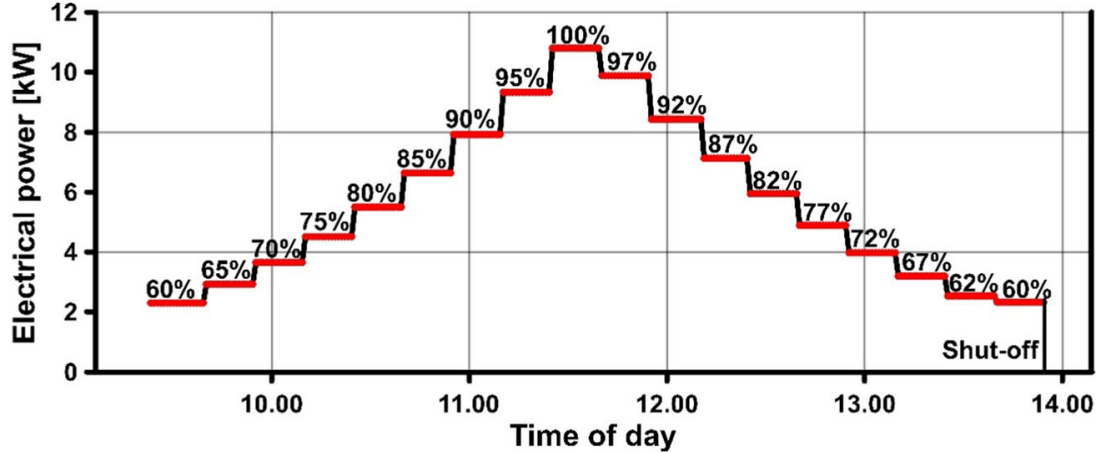

period. After the cleaning treatment, Test 3 shows a consistent increase in pumping capacity at all speeds and the pump provides $17.2 \mathrm{l} / \mathrm{s}$ with the same power consumption of $10.8 \mathrm{~kW}$, a recovery of $8,3 \%$-point compared with the initial $18.0 \mathrm{l} / \mathrm{s}$ capacity.

The variable pump performance implies that the hydraulic resistance of the system is different for each of the three tests. This is confirmed in the three differential pressure responses, which show both vertical and horizontal shifts of the pressure graphs in the data of the injection well, the production well, and of the groundwater heat exchanger (Fig. 6A-C). However, different types of performance changes are observed in these three components, which implies that the hydraulic resistance might have been altered differently in different parts of the system.

Since the sensors and the instrumentation were installed after the heat exchanger was replaced in the autumn of 2018 there are no initial on-site measurements of the heat exchangers hydraulic performance. However, the manufacturer provides a differential pressure of $2.64 \mathrm{~m}$ at $20.6 \mathrm{l} / \mathrm{s}$ pumping rate, which can serve as a reference for the tests. Plate heat exchangers are typically designed to operate within turbulent flow conditions, and this is observed for this installation as well where the groundwater heat exchanger pressure response is non-linear with respect to the flow rate (Fig. 6C). During Test 1 the pressure builds up to a maximum of $6.9 \mathrm{~m}$ of hydraulic head at $16.2 \mathrm{l} / \mathrm{s}$ flow rate, which is a substantial increase of hydraulic resistance compared with the data specified by the manufacturer. This has further increased in Test 2 to a maximum pressure head of $8.0 \mathrm{~m}$, even with a $0.5 \mathrm{l} /$ $\mathrm{s}$ lower flow rate, indicative of clogging development. After the cleaning treatment, test 3 shows a consistent decrease in pressure head for all pumping speeds. By comparing the regression results in Table 3, it is seen that both the linear and the non-linear data response have changed after the cleaning. The acid cleaning treatment has reduced the hydraulic resistance of the heat exchanger significantly.

Unlike the heat exchanger, a properly designed groundwater well should ideally have a fully linear pressure relation with respect to the pumping rate. This occurs in the injection well where the pressure increases linearly with the flow rate for all three tests. However, a consistent increase of magnitude of overpressure is observed between tests 1,2 , and 3 , respectively. The linear regression results indicate that the hydraulic resistance in the injection well has increased by $65 \%$ from test 1 in August to test 3 in October. This is indicative of clogging development. Approximately half of the increased hydraulic resistance occurs after test 2 , which indicates that the rate of clogging deposition is accelerating.

For the production well, the drawdown increases nonlinearly with respect to the flow rate and the non-linear component dominates the pressure response (Fig. 6b). A consistent increase of water level drawdown is also observed between test 1 and 2, while the data points of test 3 plots almost equal to those of test 2 . The peak drawdown was $0.3 \mathrm{~m}$ larger for test 3 at the $100 \%$ speed, but this corresponds to the
Fig. 5 Test 2 performance pyramid for the P2 and P3 pressure sensor. See Fig. 4 for test increments. At the $60 \%$ pumping speed, the pressures correspond to $-7 \mathrm{kPa}$ pressure in the $\mathrm{P} 3$ sensor. After the pump is shut off, the vacuum extends to the $\mathrm{P} 2$ sensor, and $\mathrm{a}-70 \mathrm{kPa}$ vacuum is observed in the whole groundwater pipeline (outside the $y$-axis)

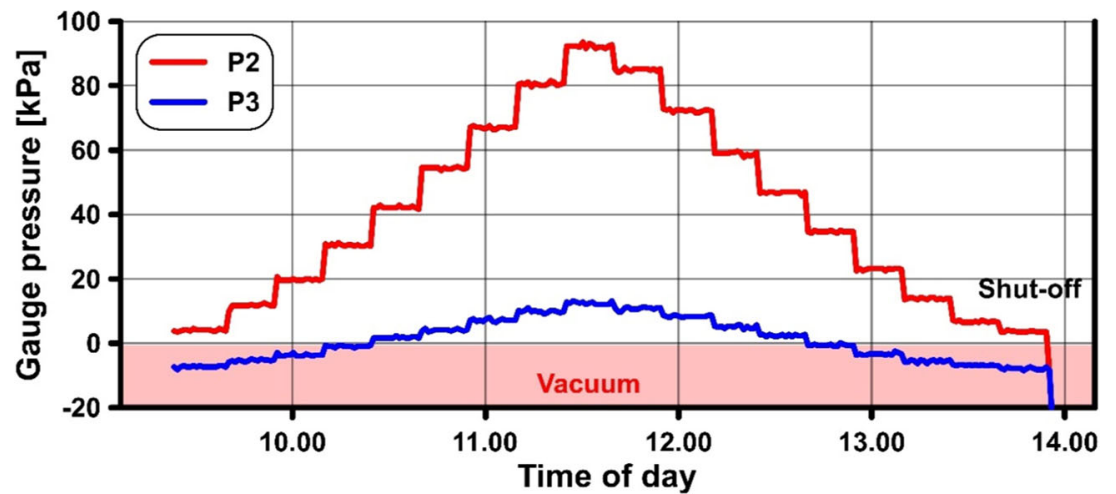


Table 3 The step-test regression results. $\Delta \mathrm{P}[\mathrm{m}]$ denotes the pressure differential and $\mathrm{Q}[1 / \mathrm{s}]$ denotes the variable flow rate. All regression curve fits are within $\mathrm{R}^{2}>0.99$. The curves are visualized in Fig. 6

\begin{tabular}{cllll}
\hline Test no. & Date & Injection well & Production well & Heat exchanger \\
\hline $\mathbf{1}$ & $\begin{array}{l}28.08 .2019 \\
\text { (Reference test) }\end{array}$ & $\Delta \mathrm{P}=0.068 \cdot \mathrm{Q}$ & $\Delta \mathrm{P}=0.018 \cdot \mathrm{Q}+0.010 \cdot \mathrm{Q}^{2}$ & $\Delta \mathrm{P}=0.064 \cdot \mathrm{Q}+0.022 \cdot \mathrm{Q}^{2}$ \\
$\mathbf{2}$ & $\begin{array}{l}\text { 08.10.2019 } \\
\text { (41 days later) }\end{array}$ & $\Delta \mathrm{P}=0.094 \cdot \mathrm{Q}$ & $\Delta \mathrm{P}=0.030 \cdot \mathrm{Q}+0.011 \cdot \mathrm{Q}^{2}$ & $\Delta \mathrm{P}=0.056 \cdot \mathrm{Q}+0.029 \cdot \mathrm{Q}^{2}$ \\
$\mathbf{3}$ & $\begin{array}{l}\text { 16.10.2019 } \\
\text { (55 days later) }\end{array}$ & $\Delta \mathrm{P}=0.112 \cdot \mathrm{Q}$ & $\Delta \mathrm{P}=0.039 \cdot \mathrm{Q}+0.010 \cdot \mathrm{Q}^{2}$ & $\Delta \mathrm{P}=0.016 \cdot \mathrm{Q}+0.011 \cdot \mathrm{Q}^{2}$ \\
& & & \\
\hline
\end{tabular}

increased pumping rate capacity of the submersible pump after the cleaning treatment. By comparing the regression results in Table 3, it is seen that it is primarily the linear data response that have changed, while the non-linear data response is virtually unchanged. The linear part of the regression results have increased by $116 \%$ from test 1 in August to test 3 in October. Approximately half of the increased hydraulic resistance occurs after test 2 , similar to that of the injection well.

\section{Discussion}

The presented step-test data demonstrate how the performance of the heat source system at Lena Terrace can be monitored with the applied surveillance procedure. The integrated sensory equipment is able to detect changes in the hydraulic performance of the submersible pump, the groundwater heat exchanger, the production well, and the injection well. The results from the three different step-test procedures show that a variety of test configurations can be applied, but a minimum number of steps are preferable when the test is applied in practice. It is shown that test 1 , with only three steps, describes the trends of the wells and the heat exchanger performances properly. The potential benefit of including more steps is not reflected in the added detail of the data of test 2 as it is possible to describe the same trend with only three of the data points. The surveillance procedure therefore only needs three steps to work in practice. This does however require a shutoff period before the test, which might not be acceptable if the building needs heating, e.g., during the winter months. As described in Gjengedal et al. (2019a), the benefit of the test 3 procedure is the possibility to perform the test without disrupting the heat production of the heating system. A step-test with four steps is thus recommended.

The step-test must be able to locate problems in the system in order to work as a surveillance tool. It is here demonstrated that the tests detect variability in the pump performance, which indicates that the hydraulic resistance of the system
Fig. 6 The injection pressure $(\Delta \mathrm{P})$ responses for the injection well (a), the drawdown $(\Delta \mathrm{P})$ of the production well (b), the differential pressure response $(\Delta \mathrm{P})$ of the heat exchanger $(\mathbf{c})$, and the electrical power supplied to the pump (d) as a function of the flow rate $(\mathrm{Q})$ for the three step-test in the Lena Terrace GWHP system. Tests 1 and 2 are performed before the maintenance of the groundwater heat exchanger in October. Test 3 is performed after the cleaning
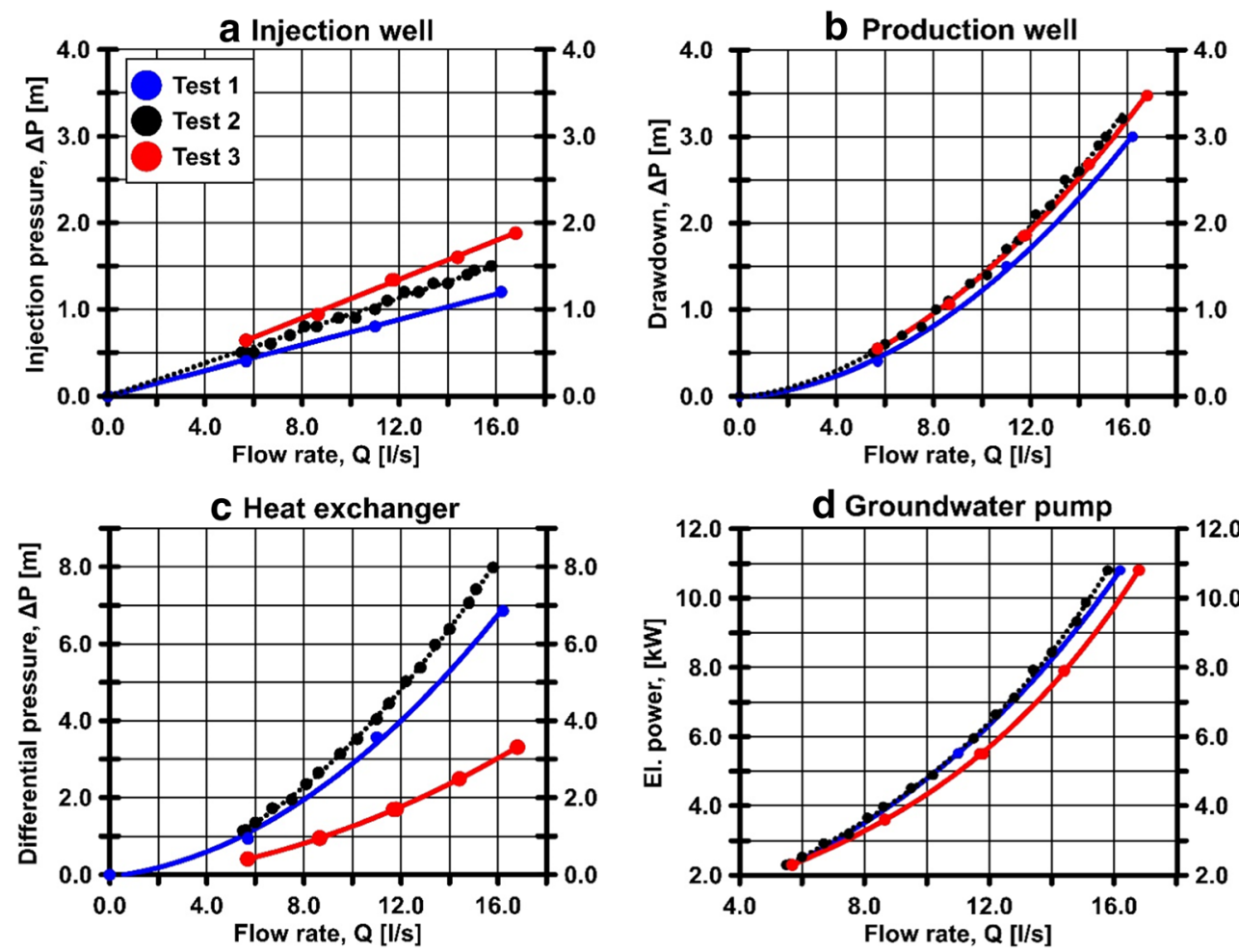
has changed. The first two tests show a reduction of production capacity for the whole groundwater system prior to the treatment of the groundwater heat exchanger. This increased hydraulic resistance indicates that clogging problems are developing in the entire system, especially in the production well, the injection well, and in the groundwater heat exchanger. Multidisciplinary competence and experience with GWHP-systems, aquifers, and groundwater wells are therefore needed to properly evaluate and interpret the results. The tests do not reveal what type of clogging material that impedes the system, but Bakema (2001) and Olsthoorn (1982) argue that monitoring over a longer timeframe can reveal different trends that are associated with various types of clogging, e.g., gas intrusion, chemical incrustations, or sediment suffusion. In this case, the test results can be interpreted and evaluated based on the system design and previous experience with faults found in the system. The tests can thus serve as a reference for other similar GWHP systems.

It was known beforehand that the groundwater heat exchanger is affected by fouling issues, typically by iron precipitates and fine soil particles clogging the heat exchanger plates. In these three tests, it is shown how this affects the hydraulic resistance of the heat exchanger. An increase in differential pressure, which is observed in tests 1 and 2, indicates that clogging and fouling development is in progress. The cleaning treatment reduced the hydraulic resistance, and test 3 demonstrates how the effects of the cleaning treatment yields a significant reduction in hydraulic resistance. The main benefit of the cleaning was presumably the improved heat transfer properties of the heat exchanger, but this could not be estimated accurately with the uncalibrated temperature sensors. The actual improvement to the thermal performance can therefore not be evaluated. However, the test shows that an increase in pumping capacity, by $1.5 \mathrm{l} / \mathrm{s}$ at maximum motor speed, is achieved after the cleaning. The test thus reveals how the lower hydraulic losses through the groundwater heat exchanger also affect the other parts of the system, e.g., through increasing the maximum drawdown in the production well at $100 \%$ pumping rate. Cleaning of the heat exchanger thus affects all parts of the system in the hydraulic sense, because the overall pumping capacity is affected.

An important benefit of the cleaning is that the pump is able to supply the necessary amount of groundwater at lower motor speeds. This reduces the electrical power consumption of the pump and the pumping cost for the installation. Some of the costs of annual cleaning of the heat exchanger are thus saved through improving the performance of the groundwater system. In the future, the performance of the heat exchanger should be monitored with calibrated temperature sensors. The heat-conducting properties of the heat exchanger are more sensitive to fouling than the hydraulic resistance. Monitoring the heat flux is thus expected to provide a more sensitive tool for fault detection in the heat exchanger (Gjengedal et al. 2019a).

The clogging material that was removed during the injection well cleaning operations and rehabilitations in 2018 and 2019 showed that the injection well was filled with a mixture of soil sediments and particles. These sediments were found to have been derived from suffusion through the production well screen. This has likely occurred this time as well. The increased hydraulic resistance observed in the injection well pressure response is a clear indication that clogging development is in progress. Similar pressure responses are described by Olsthoorn (1982) for injection well clogging in general. The data display a gradual buildup of the pressure response over the 55-day period, and the regression results (Table 3) show that the rate of clogging deposition is accelerating. In order to ensure continuous and reliable operation of the GWHP system, it is therefore necessary to perform additional maintenance on the injection well screen but also the production well to stop the suffusion of particles.

Suffusion of soil particles through the production well screen is known to affect the production well performance in a distinct manner (Olsthoorn 1982; Van Beek 2007). The presented tests demonstrate that the drawdown in the production well react non-linearly to the flow rate (Fig. 6b), deviating from the anticipated fully linear drawdown curve expected from a properly design groundwater well. The question is whether this excessive drawdown is a sign of clogging of the production well screen or not. By comparing the pressure response of tests 2 and 3, relative to test 1 , it is observed that there is an increased hydraulic resistance in the well. However, the relative increase in drawdown originates from an increase of the linear pressure responses, while the nonlinear pressure response is virtually unaffected. The majority of linear head losses originate from aquifer losses and/or well screen losses (Houben 2015a). This increase of linear head losses is therefore a likely sign of clogging of the well screen and/or the aquifer.

The lack of change in the non-linear component indicates that the cause of these losses has not been altered throughout the test period. Non-linear drawdown losses are associated with inertial losses that occur at high velocities (e.g., convective acceleration or turbulence). The fully linear response of the injection well reveals that the local soil conditions do not induce non-linear losses in the flow for the pumping rates tested. The production well has similar soil conditions, but compared with the injection well, it has slightly higher flow velocities through the well screen because of the shorter screen length. Assuming an even distribution of the flow along the entire well screen, the average maximum flow velocity $(17.2 \mathrm{l} / \mathrm{s}$ flow rate at $100 \% \mathrm{~Hz})$ through the production well screen is $1.81 \mathrm{~cm} / \mathrm{s}$, while it is $1.09 \mathrm{~cm} / \mathrm{s}$ through the injection well screen. The $1.81 \mathrm{~cm} / \mathrm{s}$ velocity is perhaps high enough to induce some non-linear losses in the aquifer 
(Houben 2015a), but not to the degree that is measured here. The difference in screen flow velocity does therefore not explain the dominant non-linear component of the production well pressure response.

The most likely cause to these non-linear losses is the relatively large contraction and expansion of the flow channel in the well-bore segment around the submersible pump motor. Houben (2015b) states that the upwards flow velocity in a well should be kept below $1.5 \mathrm{~m} / \mathrm{s}$ to maintain well losses at an acceptable level. This is ensured in the well-bore itself, but not in the section around the pump. The SP60-5-MS6000 submersible pump (Grundfos 2019) has a motor diameter of $139.5 \mathrm{~mm}$. The internal well diameter of $158.0 \mathrm{~mm}$ then provides a $9.25-\mathrm{mm}$ annular channel opening past the pump motor, which is very narrow for the $17.2 \mathrm{l} / \mathrm{s}$ flow rate. The average flow velocity past the $0.6 \mathrm{~m}$ long motor will then be approximately $3.9 \mathrm{~m} / \mathrm{s}$, indicating highly turbulent flow conditions. This channel opening is unchanged from test 1-test 3, and it is therefore reasonable that the non-linear component is unchanged as well. The non-linear behavior is thus not likely caused by clogging, but by a faulty well design with a too narrow well diameter.

Apart from the clogging issues that are detected, the tests reveal that the production well water level drawdown is too large to ensure that the pump operates reliably. The submersible pump requires $5 \mathrm{~m}$ of overpressure (NPSH) to operate reliably at $100 \% \mathrm{~Hz}$ motor speed (Grundfos 2019). With $3.5 \mathrm{~m}$ of drawdown, the pump operates with $2.9 \mathrm{~m}$ of overpressure, and the pump is thus subjected to increased risks of, e.g., flow separation and vacuum pressures at the suction inlet and internal cavitation at the pump impellers (Mackay 2004). To ensure continuous and reliable operation of the GWHP system, it is necessary to perform additional maintenance on the production well screen or to limit the pumping rate to $80 \%$ of the maximum capacity where $4 \mathrm{~m}$ of NPSH is sufficient.

The tests also reveal that parts of the groundwater pipeline operate with vacuum pressures. Vacuum pressure can potentially trigger exsolution of gases that are dissolved in the groundwater (Banks 2012; Snijders and Drijver 2016; Gjengedal et al. 2019b). The tests thus indicate that the system has an unfavorable design configuration with respect to the local groundwater conditions, which can potentially be the underlying reason for the clogging issues that has troubled this installation since 2003.

\section{Conclusions}

The performance of the Lena Terrace groundwater heat pump system has been monitored with a step-test surveillance procedure. Results from three versions of the test demonstrate that the test can be performed with a minimum of four steps, each of 15-min duration, while the GWHP system is active and producing heat. The results demonstrate that the surveillance test can detect changes in the hydraulic resistance of the groundwater circuit and locate clogging problems within all of the relevant system components in the groundwater circuit simultaneously. At the Lena Terrace GWHP system, these tests indicate a gradual increase of hydraulic resistance with time, which verify that clogging issues are continuously developing in the injection well, the production well, and in the groundwater heat exchanger. Cleaning of the heat exchanger has increased the pumping capacity by $8.3 \%$ points, but continuous clogging of the injection well and the production well necessitates further maintenance to ensure a reliable operation. These results can function as a reference for other GWHP systems with similar design configurations.

Acknowledgments Open Access funding provided by Norwegian University of Science and Technology (incl St. Olavs Hospital Trondheim University Hospital). This work was conducted as a part of the research project Optimal Resource Utilization of Groundwater for Heating and Cooling in Melhus and Elverum (ORMEL). The project is a cooperation between the municipalities of Melhus and Elverum, the Norwegian University of Science and Technology, Asplan Viak AS, and the Geological Survey of Norway. We would like to thank all the involved institutions and persons for cooperation and financial contributions.

Funding The Regional Research Funds in Mid-Norway (grant number 209074) funded this research.

\section{Compliance with ethical standards}

Conflict of interest The authors declare that they have no conflict of interest.

Open Access This article is licensed under a Creative Commons Attribution 4.0 International License, which permits use, sharing, adaptation, distribution and reproduction in any medium or format, as long as you give appropriate credit to the original author(s) and the source, provide a link to the Creative Commons licence, and indicate if changes were made. The images or other third party material in this article are included in the article's Creative Commons licence, unless indicated otherwise in a credit line to the material. If material is not included in the article's Creative Commons licence and your intended use is not permitted by statutory regulation or exceeds the permitted use, you will need to obtain permission directly from the copyright holder. To view a copy of this licence, visit http://creativecommons.org/licenses/by/4.0/.

\section{References}

Bakema G (2001) Well and borehole failures in UTESS. State of the art 2000, 2nd edn. IF Technology BV, Arnhem

Banks D (2012) An introduction to Thermogeology: ground source heating and cooling, 2nd edn. Wiley-Blackwell, Chichester

Bloemendal M, Olsthoorn T, van de Ven F (2015) Combining climatic and geo-hydrological preconditions as a method to determine world potential for aquifer thermal energy storage. Sci Total Environ 538: 621-633. https://doi.org/10.1016/j.scitotenv.2015.07.084 
Brøste HM (2017) Vannkvalitet knyttet til grunnvannsbaserte grunnvarmeanlegg i Melhus og Elverum [eng: Water quality with respect to open loop GSHP systems in Melhus and Elverum]. Master thesis, Norwegian University of Science and Technology Trondheim (NTNU Trondheim) (in Norwegian)

Gehlin S, Andersson O (2019) Geothermal energy use, country update for Sweden. Proceedings of the European Geothermal Congress, Den Haag, The Netherlands, 11-14 June

Gjengedal S, Ramstad RK, Hilmo BO, Frengstad BS (2018) Video inspection of wells in open loop ground source heat pump systems in Norway. Editor: prof. Jeffrey D. Spitler. International ground source heat pump association, Oklahoma. In IGSHPA conference proceedings 2018. https://doi.org/10.22488/okstate.18.000025

Gjengedal S, Ramstad RK, Hilmo BO, Frengstad BS (2019a) Fouling and clogging surveillance in open loop GSHP systems. A systematic procedure for fouling and clogging detection in the whole groundwater circuit. Bull Eng Geol Environ. https://doi.org/10.1007/ s10064-019-01556-5

Gjengedal S, Stenvik LA, Storli PT, Ramstad RK, Hilmo BO, Frengstad BS (2019b) Design of groundwater heat pump systems. Principles, tools and strategies for controlling gas and precipitation problems. Energies 12:3657. https://doi.org/10.3390/en12193657

Grundfos (2019) Grundfos data booklet. SP engineering manual https:// nogrundfoscom/campaigns/download-sp-engineering-manualhtml Accesses on: 29 November 2019

Hellestveit MS (2018) 3D-modellering av grunnvannstrømning og varmetransport i akviferen i Melhus sentrum - en kvartær- og hydrogeologisk tolkning, med vurdering av uttakskapasitet. [eng: 3D modeling of groundwater flow and thermal development in the Melhus aquifer - an evaluation of quaternary and hydrogeological conditions and exploitation limitations] master thesis. Trondhiem. NTNU. (in Norwegian)
Houben GJ (2015a) Review: hydraulics of wells - the flow laws and influence of geometry. Hydrogeol J 23:1633-1657. https://doi.org/ 10.1007/s10040-015-1312-8

Houben GJ (2015b) Review: hydraulics of water wells - head losses of individual components. Hydrogeol J 23:1659-1675. https://doi.org/ 10.1007/s10040-015-1313-7

Kruseman GP, de Ridder NA (1994) Analysis and evaluation of pumping test data, 2nd edn. Wageningen, International Institute for Land Reclamation and Improvement

Mackay R (2004) The practical pumping handbook. Elsevier, Oxford

Melo LF, Bernardo CA, Bott TR (1988) Fouling science and technology. Kluwer, Dordrecht

Müller-Steinhagen H (2000) Heat exchanger fouling: mitigation and cleaning technologies: handbook. Publico Publications, Essen

Olsthoorn TN (1982) The clogging of recharge wells, technical report. The Netherlands Waterworks' testing and research institute KIWA, Rijswijk

Rees S (2016) Advances in ground-source heat pump systems. Woodhead Publishing, Amsterdam

Riise MH (2015) Praktisk guide for grunnvarmeanlegg basert på oppumpet grunnvann - Hydrogeologiske forundersøkelser, etablering, drift og oppfølging med utgangspunkt i erfaringer fra etablerte anlegg i Melhus sentrum [eng: Guide to a better design and operation of groundwater heat pump systems - with examples from Melhus]. Master thesis, NTNU Trondheim (in Norwegian)

Snijders AL, Drijver BC (2016) Open-loop heat pump and thermal energy storage systems. In: Rees S (ed) Advances in ground-source heat pump systems, 1st edn. Woodhead Publishing, Amsterdam, pp 247268

Stene J (2001) Varmepumper: grunnleggende varmepumpeteknikk [in English: Heat pumps: basics] Trondheim, SINTEF Energi

Van Beek C (2007) Cause and prevention of clogging of wells. Abstracting groundwater from unconsolitaed aquifers. $\mathrm{PhD}$ Thesis, Vrije University, Amsterdam 